\title{
Aa. Vv., Le lent brassement des livres, des rites et de la vie. Mélanges offerts à James Dauphiné, textes réunis par Monique Léonard, Xavier Leroux et François Roudaut
}

\section{Dario Cecchetti}

\section{OpenEdition}

\section{Journals}

Edizione digitale

URL: http://journals.openedition.org/studifrancesi/6600

DOI: $10.4000 /$ studifrancesi.6600

ISSN: 2421-5856

\section{Editore}

Rosenberg \& Sellier

\section{Edizione cartacea}

Data di pubblicazione: 1 septembre 2010

Paginazione: $354-355$

ISSN: 0039-2944

\section{Notizia bibliografica digitale}

Dario Cecchetti, «Aa. Vv., Le lent brassement des livres, des rites et de la vie. Mélanges offerts à James Dauphiné, textes réunis par Monique Léonard, Xavier Leroux et François Roudaut», Studi Francesi [Online], 161 (LIV | II) | 2010, online dal 30 novembre 2015, consultato il 14 janvier 2021. URL: http:// journals.openedition.org/studifrancesi/6600 ; DOI: https://doi.org/10.4000/studifrancesi.6600

Questo documento è stato generato automaticamente il 14 janvier 2021.

$$
\text { opere derivate } 4.0 \text { Internazionale. }
$$

Studi Francesi è distribuita con Licenza Creative Commons Attribuzione - Non commerciale - Non 


\title{
Aa. Vv., Le lent brassement des livres, des rites et de la vie. Mélanges offerts à James Dauphiné, textes réunis par Monique Léonard, Xavier Leroux et François Roudaut
}

\author{
Dario Cecchetti
}

\section{NOTIZIA}

AA. VV., Le lent brassement des livres, des rites et de la vie. Mélanges offerts à James Dauphiné, textes réunis par Monique LÉONARD, Xavier LEROUX et François ROUDAUT, Paris, Champion, 2009 («Presses Universitaires de la Faculté des Lettres de Toulon, Babeliana», 11), pp. 1033.

1 Francesista e comparatista di primo piano, James Dauphiné ha sviluppato interessi in campi e verso epoche diverse, in particolare per quanto concerne la letteratura medievale, il Cinquecento ed anche la letteratura contemporanea, e pertanto si comprende come i Mélanges che gli vengono offerti coprano queste tre aree (Medievalia, Humanistica, Contemporanea), ma dato che per tutto l'arco della sua produzione si è qualificato in primo luogo, per le sue scelte, come un seiziémiste è comprensibile che il nucleo principale dei saggi pubblicati riguardi l'Umanesimo e il Rinascimento fino alle soglie del Barocco. Riteniamo pertanto di segnalare in questa sezione (anche se è impossibile rendere conto di tutti i singoli interventi, a causa della loro ricchezza e complessità) la parte preponderante consacrata al Rinascimento che fa del volume un importante strumento di lavoro per i cinquecentisti.

2 I contributi concernenti l'Umanesimo e il Cinquecento sono i seguenti: Cesare VASOLI, Le profezie e la loro tradizione nella cultura quattrocentesca (pp. 223-247), Véronique DUCHÉ- 
GAVET, L“"Heptaméron" et la fiction sentimentale (pp. 249-265), Estelle GROSSO, Le rire dans l'“Heptaméron" de Marguerite de Navarre (pp. 267-283), Philippe DE LAJARTE, La vision des arts libéraux dans le troisième libre des "Prisons": un humanisme théocentrique (pp. 285-305), Catherine LANGLOIS-PÉZERET, Des "Poemata" aux "Fata": Dolet, metteur en scène de sa propre carrière (pp. 307-324), Xavier LEROUX, L“'Abraham sacrifiant” de Théodore de Bèze: entre mystère et tragédie (pp. 325-344), Frank LESTRINGANT, La terre percée et la lettre des antipodes. À propos du IV dialogue du "Cymbalum mundi" (pp. 345-358), Josiane RIEU, L'inspiration et l'harmonie du monde dans les "Odes" de Ronsard (pp. 359-382), Yvonne BELLENGER, Les "Inventions" de Du Bellay (1552): une promesse de conversion? (pp. 383-396), Bénédicte Boudou, Henri Estienne et la simplicité de l'âge d'or dans l'“Apologie pour Hérodote" (pp. 397-420), Jean-Claude MARGoLIN, Théorie et pratique de l'énigme chez Alexandre Van den Busche, alias Sylvain de Flandre (pp. 421-453), Richard CRESCENZO, La réflexion sur les langues dans l'œuvre de Louis Le Roy, traducteur et historien (pp. 455-469), Jean-Luc MARTINET, Quelle dignité pour l'homme dans les "Semaines" de Du Bartas? (pp. 471-487), Emmanuel Rousse, Le statut de la digression dans "La Sepmaine" de Du Bartas (pp. 489-527), Denis BJAÏ, Un commentateur en quête d'auteur: Pantaléon Thévenin entre Ronsard et Du Bartas (pp. 529-546), Gilles BANDERIER, Johann Valentin Andreae, rosicrucien et traducteur de Du Bartas (pp. 547-571), Myriam JACQUEMIER, Dieu messager, Dieu imagé. Deux rhétoriques du sacré à la fin de la Renaissance (pp. 573-600), Guylaine PINEAU, Ambroise Paré et le «beau mot 'Abracadabra'» (pp. 601-623), Christian DESPLAT, Brantôme, "Discours sur les colonels de l'infanterie de France": l'invention du soldat moderne (pp. 625-651), Franco GIACONE, Pontus de Tyard et le Vatican. Trois documents inédits de Pontus de Tyard au pape Paul III (pp. 653-679), François ROUDAUT, Remarques sur 'fantaisie' dans "L'Encyclie" (1571) et dans "La Galliade" (1578) de Guy Le Fèvre de La Boderie (pp. 681-698), Hélène CHARPENTIER, Pierre-Victor Cayet, 'cronologue' de la Navarre et de la France médiévales (pp. 699-714), Claude-Gilbert DuBoIs, Dieux cruels et victimes expiatoires. Passions, pressions, répressions chez deux héroïnes littéraires du XVII siècle: Lady Macbeth de Shakespeare et Phèdre de Racine (pp. 715-733), Christine QUEFFÉLEC, Les "Sonnets" de Shakespeare, une illustration du monde à l'envers? (pp. 735-745), Marie-Madelaine FRAGONARD, La gloire et la honte: les portraits aux murs des bibliothèques (pp. 747-766), Frank GREINER, Amour et magie dans quelques romans français de l'âge baroque (pp. 767-788), Jean-Claude TERNAUX, "Hector" de Montchrestien et le songe tragique (pp. 789-805).

3 Come appare da una rapida scorsa a questo indice, si tratta di contributi corposi in cui si alternano approcci diversi (storici e filologici, tematici e di storia delle idee). In alcuni casi - per esempio, per gli studi consacrati a Du Bartas (Martinet, Rousse, Bjaï, Banderier, Jacquemier), autore più di ogni altro caro a Dauphiné - ci troviamo in presenza di un corpus coerente, ricco di suggerimenti originali che aprono piste di ricerca. Particolare attenzione è rivolta a una delle tematiche - o meglio, delle aree di indagine - centrale negli studi di Dauphiné, quella del rapporto letteratura-scienza: attenzione esemplare in questi Mélanges, ricordando anche solo l'interessante articolo sull'intuizione dello spazio, a partire dall'analisi di un testo del cymbalum mundi (Lestringant). Così, la perlustrazione di terreni meno battuti, come nei saggi sui poemata di Dolet (Langlois-Pézeret), sulla rappresentazione dell'età dell'oro in Henri Estienne (Boudou) o su generi minori come l'enigma (Margolin), o la nuova documentazione apportata a grandi discussioni umanistiche, come il dibattito sulle lingue (Crescenzio), o la riflessione sulla poetica ronsardiana (Rieu), offrono materiale nuovo agli studiosi. 